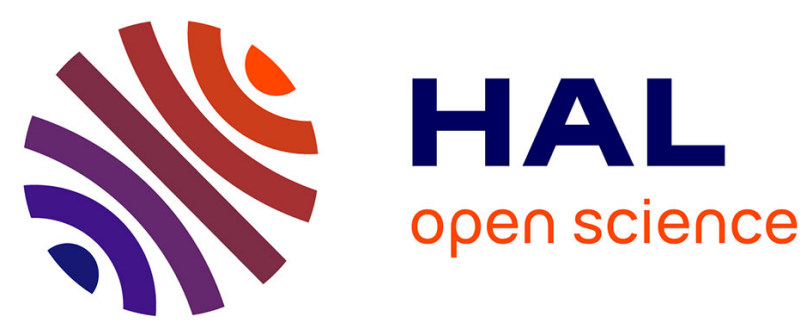

\title{
Motivation and Dropout in Female Handballers: A 21-month Prospective Study
}

Philippe Sarrazin, Robert Vallerand, Emma Guillet, Luc Pelletier, François Cury

\section{- To cite this version:}

Philippe Sarrazin, Robert Vallerand, Emma Guillet, Luc Pelletier, François Cury. Motivation and Dropout in Female Handballers: A 21-month Prospective Study. European Journal of Social Psychology, 2002, 32 (3), pp.395-418. 10.1002/ejsp.98 . hal-00388553

\section{HAL Id: hal-00388553 https://hal.science/hal-00388553}

Submitted on 26 May 2009

HAL is a multi-disciplinary open access archive for the deposit and dissemination of scientific research documents, whether they are published or not. The documents may come from teaching and research institutions in France or abroad, or from public or private research centers.
L'archive ouverte pluridisciplinaire HAL, est destinée au dépôt et à la diffusion de documents scientifiques de niveau recherche, publiés ou non, émanant des établissements d'enseignement et de recherche français ou étrangers, des laboratoires publics ou privés. 
Motivation and Dropout in Female Handballers:

A 21-month Prospective Study

P. Sarrazin ${ }^{1}$, R. Vallerand ${ }^{2}$, E. Guillet ${ }^{1}$, L. Pelletier $^{3} \&$ F. Cury ${ }^{4}$

1. Université Grenoble 1. France.

2. Laboratoire de Recherche sur le Comportement Social et Département de

Psychologie Université du Québec, Montréal, Canada.

3. School of Psychology. University of Ottawa, Ontario, Canada.

4. Université de la Méditerranée, Marseille. France.

European Journal of Social Psychology, 32(3), 395-418.

Submission date: June, $19^{\text {th }}, 2000$

Revision accepted: September, $5^{\text {th }}, 2001$

Address for correspondence:

Philippe Sarrazin, Ph.D.

Laboratoire d'Etudes et de Recherches sur 1'Offre Sportive - UPRES 540

UFRAPS - Université Grenoble I. BP 53 - 38041 Grenoble Cedex 9 - France.

Phone: 334765142 29; Fax: 33476514469

e-mail: philippe.sarrazin@ujf-grenoble.fr

Acknowledgements:

Preparation of this article was facilitated through a grant from the French Federation of Handball to the first author and grants from the Social Sciences and Humanities Research Council of Canada (SSHRC), Le Fonds pour la Formation des Chercheurs et l'Aide à la Recherche (FCAR Québec), and the Université du Québec à Montréal (UQAM) to the second author. 


\section{ABSTRACT}

The purpose of this study was to test a motivational model of sport dropout that integrates the 4 stage-causal sequence proposed by the Hierarchical Model of Vallerand (1997) and elements from achievement goal theory (Nicholls, 1989). The model posits that a task involving motivational climate facilitates, while an ego-involving climate undermines, perceptions of competence, autonomy, and relatedness. In turn, feeling incompetent, non autonomous, and unrelated to others undermines self-determined motivation toward handball which leads to the intention of dropping out of handball. Finally, such intentions are implemented later on. Three-hundred and thirty-five females handballers completed a motivation questionnaire and were followed for 21months. Results from structural equation modeling analyses provided basic support for the model. Findings are discussed in light of their theoretical and applied implications.

Running head: Dropout in Female Handballers

KEY WORDS : Dropout - Sport - motivation - Self-determination - Female athlete Hierarchical model 
In France, as in many western countries more and more people engage in sport (see for example, Ewing \& Seefeldt, 1996; Russell, Allen, \& Wilson, 1996; Wankel \& Mummery, 1996). In 1997, 14 million individuals were registered in French sporting federations (Data of the Ministry for Youth and Sports, 1997). However, this massive passion for sport masks a paradox: a massive number of teenagers, particularly girls, drop out from sport every year (Gould, 1987; Russell et al., 1996; Sallis \& Patrick, 1996; Wankel \& Mummery, 1996). For example, 50\% of Frenchwoman handball players, drop out between 13 and 15 years of age (Guillet \& Sarrazin, 1999, unpublished data, University of Grenoble, France). Given the multiple benefits of the regular practice of physical activity revealed in many studies (see Martinsen \& Stephens, 1994, for a review), it is unfortunate that a large number of children and teenagers terminate their participation in a physical activity. Moreover, some experts identified adolescents as a group "at risk" due to declining physical activity and subsequent health-related behaviour and outcomes (Sallis \& Patrick, 1996). If the goal is to increase the physical activity level of the teenage population, more research is needed with regard to factors related to their physical activity.

A key variable to look at when attempting to predict sport participation is motivation (Vallerand, Deci, \& Ryan, 1987; Vallerand \& Losier, 1999; Vallerand \& Rousseau, 2001). "Motivation represents the hypothetical construct used to describe the internal and/or external forces that produce the initiation, direction, intensity, and persistence of behaviour" (Vallerand \& Thill, 1993, p. 18, translated by the authors). Various motivational theories can be useful with respect to the study of sport dropout (see Gould, 1987; Weiss \& Chaumeton, 1992; Sarrazin \& Guillet, 2001, for reviews). However, a model that seems particularly well suited to study the dropout issue is the 
Hierarchical Model of Intrinsic and Extrinsic Motivation (HMIEM, Vallerand, 1997; Vallerand \& Ratelle, in press). Drawing its roots in self-determination theory (Deci \& Ryan, 1985, 1991, 2000), the HMIEM model has furthered our understanding of motivational processes involved in the dropout issue in education (Vallerand, Fortier, \& Guay, 1997) and has received much support in the field of sport and physical activity (see Vallerand \& Grouzet, 2001; Vallerand \& Perreault, 1999; Vallerand \& Rousseau, 2001). The model makes a number of propositions with respect to the determinants and consequences of motivation. Among other things, the model proposes a 4 stage-causal sequence: "Social factors $\rightarrow$ Psychological Mediators $\rightarrow$ Types of Motivation $\rightarrow$ Consequences". Because such a sequence has led to the prediction of high school dropout (Vallerand et al., 1997), it will serve as the basis of the present study. The model is described below.

\section{Types of Motivation: From a Dichotomy to a Continuum of Sport Motives}

Early research on intrinsic and extrinsic motivation emphasised the dichotomy between the two concepts. However, in line with Self-Determination Theory (Deci \& Ryan, 1985, 1991, 2000; Ryan \& Deci, 2000), the HMIEM model considers that this dichotomy is insufficient to adequately depict human behaviour. It views motivation in terms of varying degrees of self-determination, thereby leading to a continuum of different types of motives. The highest level of self-determination is assumed to be inherent in intrinsic motivation. This refers to doing an activity for the pleasure it provides or for its own sake (Deci, 1971). Vallerand and his colleagues (Pelletier, Fortier, Vallerand, Tuson, Brière, \& Blais, 1995; Vallerand, 1997; Vallerand et al., 1992, 1993 ; Vallerand \& Losier, 1999) have proposed the existence of three forms of intrinsic motivation : intrinsic motivation toward knowledge (which involves engaging 
in sport for the pleasure and satisfaction that one experiences while learning, exploring or trying to understand something new), toward accomplishment (which results from practising a sport for the pleasure and satisfaction of out-doing oneself, and the process of trying to reach new personal objectives), and toward experiencing stimulation (which refers to engaging in sport in order to experience stimulating sensations (e.g., sensory pleasure, aesthetic experiences, as well as fun and excitement) derived from one's engagement in the activity).

On the other hand, extrinsic motivation is instrumental in nature and is experienced when someone engages in an activity as a means to an end. However, unlike some perspectives that view extrinsically motivated behaviour as invariantly nonautonomous, three major types of extrinsic motivation have been proposed (Deci \& Ryan, 1985, 1991; Ryan, Connell, \& Deci, 1985; Vallerand, 1997), which vary in terms of the level of self-determination inherent in each one. From lower to higher levels of self-determination, they are external regulation, introjected regulation, and identified regulation. External regulation ' $\ldots$ is the classic case of extrinsic motivation in which people's behaviour is controlled by specific external contingencies. People behave in order to attain a desired consequence such as tangible rewards or to avoid a threatened punishment' (Deci \& Ryan, 2000, p. 236). An athlete who participates in sport in order to receive trophies and awards or to avoid negative consequences (e.g., criticisms or punishments from parents) is acting out of external regulation. Whereas with external regulation control of behaviour comes from contingent consequences that are administered by others, with introjected regulation, contingent consequences are administered by individuals to themselves. As stated by Deci and Ryan (2000): 'Introjection represents a partial internalisation in which regulations are in the person 
but have not really become part of the integrated set of motivations, cognitions, and affects that constitute the self' (p. 236). Introjected reasons for doing an activity are typified by "should" and "must". The prototypic examples are contingent self-worth (pride) or threats of guilt and shame (Deci \& Ryan, 2000). An athlete who says that s/he is practising sport "Because I would feel bad if I was not taking time to do it" displays introjected regulation. Finally, when motivated out of identified regulation, the athlete choicefully decide to engage in behaviour that is not interesting per se, but nevertheless important, because it helps him/her reach valued personal goals. In other words, the activity is still performed for extrinsic reasons, but it is internally regulated and self-determined. Athletes who participate "Because it is a good way to learn lots of things which could be useful to me in other areas of my life" exemplifies identified regulation.

Finally, a third motivational concept is necessary to provide a more complete account of human behaviour. This concept, termed amotivation (Deci \& Ryan, 1985, 2000) refers to behaviour that is neither intrinsically nor extrinsically motivated, and which is situated at the lowest level of the self-determination continuum. Quite similar to the concept of learned helplessness (Abramson, Seligman, \& Teasdale, 1978), amotivation refers to perceptions of lack of contingency between actions and outcomes. This is likely to occur when individuals experience feelings of incompetence and lack of control (Deci \& Ryan, 1985, 2000). For instance, athletes who say that they really don't know why they play handball any more are displaying amotivation toward their sport.

In sum, the HMIEM underlines five different types of motivation organised in terms of the extent to which the motivations are autonomous or emanate from the self (i.e., are self-determined). Intrinsic motivation is highly autonomous and represents the 
prototypic instance of self-determination, whereas amotivation is the least selfdetermined type of motivation. Identified regulation, introjected regulation and external regulation are three different forms of extrinsic motivation ordered from higher to lower levels of self-determination, that fall between intrinsic motivation and amotivation.

Much research now supports the self-determination continuum in the realm of sport (see Vallerand \& Losier, 1999, for a review)

$\underline{\text { Social Factors as Determinants of Sport Motivation: The Coach's Behaviour }}$

Social factors are expected to influence motivation (Vallerand, 1997). In sport contexts, coaches' behaviour can have a crucial impact on athletes' motivation (Vallerand \& Losier, 1999). Coaches design practice sessions, group children, give recognition, evaluate performance, share their authority and they shape the sport setting. In sum, they establish a "motivational climate" (Ames, 1992) which can have an important impact on athletes' self-determined motivation. Researchers have mostly been interested in the effects of two interactive styles: a controlling style, one in which the coach acts in a coercive, pressuring, authoritarian way and an autonomy-supportive style, where the coach supports freedom, encourages autonomy and implicates individuals in the decision process. Results in contexts as diverse as education (Deci, Schwartz, Sheinman, \& Ryan, 1981; Gottfried, Fleming, \& Gottfried, 1994; Vallerand et al., 1997), sport (Goudas, Fox, Biddle, \& Underwood, 1995; Pelletier et al., 1995; Pelletier, Fortier, Vallerand, \& Brière, in revision) and work (e.g., Pelletier \& Vallerand, 1996) revealed that supervisors who adopt an autonomy-supportive style produce an increase in self-determined forms of motivation (intrinsic motivation and identified regulation), but also a decrease in amotivation and external regulation. On the other hand, supervisors who adopt a controlling style produce a decrease in self-determined 
forms of motivation, but also an increase in amotivation and in certain cases external regulation (see, Vallerand, 1997, for a review).

More recently, task or ego involving climates were also suggested as a context that could have an impact on athletes' motivation. These variables are related to achievement goal theory (AGT; Ames, 1992; Dweck, 1986; Nicholls, 1989; see, Duda, 2001; Duda \& Hall, 2000; Roberts, 2001; Roberts, Treasure, \& Kavussanu, 1997, for reviews in sport context). The central tenet of AGT is that the goal of an individual is to strive to demonstrate competence in achievement contexts. The existence of two independent goals is now acknowledged. In the first case (labelled task involvement), the goal of the individual is to master tasks, to solve problems or to make progress. In the second case (labelled ego involvement), the goal of the individual is to demonstrate of a high ability or to avoid of being perceived as incompetent. AGT generally considers that a person's goal in a particular setting is a function of situational and dispositional (task and/or ego orientation) factors. Situational factors, like the coach's behaviour, can be more or less task and/or ego involving (see, Duda, 2001, for a review). Emphasis on the learning process, investment, progress, and the promotion of cooperation among team members constitute examples of task-involving structures of the climate. By contrast, emphasis on competition where "winning is everything", mistakes are punished, reinforcement and attention are differentially provided as a function of ability level, and where rivalry is fuelled among players of the same team constitute examples of an ego-involving climate. AGT suggests that the development of intrinsic motivation is most likely when task involvement is encouraged, because an individual invests in an activity for its own sake and thus, considers it to be an end in itself(Nicholls, 1989). In contrast, when ego involvement is encouraged, the self- 
determined motivation decreases, because (1) the activity becomes a means to an end (Nicholls, 1989), (2) the successful outcomes are perceived as less under the person's volitional control (Duda \& Hall, 2000), and (3) a feeling of pressure to maintain selfesteem is experienced (Ryan \& Deci, 2000). Several correlational studies have provided support for the association between achievement goals (dispositional goals and/or perceived achievement climate) and intrinsic motivation. In general, these studies have shown that task-involvement is positively related to intrinsic motivation while egoinvolvement is not, or is moderately and negatively related to it (see, Duda, 2001; Duda \& Hall, 2000; Ntoumanis \& Biddle, 1999, for reviews). In addition, a number of experimental studies have shown that relative to task-involvement, ego-involving manipulations produce significantly lower levels of intrinsic motivation (e.g., Butler, 1988; Harackiewicz, Abrahams, \& Wageman, 1987; Ryan, 1982; Ryan, Koestner, \& Deci, 1991; Vallerand, Gauvin, \& Hallivel1, 1986; see, Rawsthorne \& Elliot, 1999, for a meta-analytic review).

\section{Psychological Mediators}

The impact of social factors on motivation is hypothesised to take place mainly through people's perceptions of social events (Vallerand, 1997). In other words, it is not the objective context which counts, but how an individual perceives it. Thus, the HMIEM model posits that peoples' perceptions of autonomy, competence, and relatedness constitute mediators of the effects of social factors on their intrinsic motivation, because these perceptions relate to fundamental human needs that individuals seek to satisfy (Connell \& Wellborn, 1991; Deci \& Ryan, 1985, 1991; Vallerand, 1997). Consequently social factors that facilitate feelings of competence, autonomy or relatedness will increase intrinsic motivation, whereas those that impair such perceptions will have a 
negative effect on intrinsic motivation and self-determined forms of motivation and will facilitate non-self-determined forms of motivation and amotivation (Vallerand, 1997). In the sport context, coaches' behaviour is expected to have important effects on athletes' motivation through the influence the very climate they help create will have on athletes' perceptions of competence, autonomy, and relatedness. Results from a recent study (Blanchard \& Vallerand, 1996, Perceptions of competence, autonomy, and relatedness as psychological mediators of the social factors - contextual motivation relationship; unpublished manuscript, University of Quebec at Montreal) with basketball players provided support for the mediating hypothesis. A path analysis revealed that the more the coach was perceived as autonomy-supportive by his or her athletes, the more competent, autonomous, and related to the team they felt. In turn, athletes' perceptions of competence, autonomy, and relatedness had positive effects on their self-determined motivation towards basketball.

\section{Dropping Out of Sport as a Motivational Consequence}

The fourth stage of the HMIEM corresponds to the affective, cognitive and behavioural consequences of motivation (Vallerand, 1997; Vallerand \& Losier, 1999). Several studies over the past two decades (see Ryan, 1995; Vallerand, 1997, for reviews) have shown that self-determined forms of motivation (intrinsic motivation and identified regulation) are positively associated with positive consequences (e.g., enhanced learning, greater interest, greater effort, better performance, etc.), whereas least self-determined forms of motivation (external regulation and amotivation) are associated with negative outcomes. In addition, some laboratory studies have revealed that individuals who are induced to participate in an activity for extrinsic reasons (i.e., are motivated in a non self-determined way) persist less during a free-choice period than 
those who are intrinsically motivated (see, Deci \& Ryan, 1985; Pelletier \& Vallerand, 1993, for a review). This is especially likely to be the case when subsequent engagement in the activity is not compulsory (Vallerand et al., 1997).

In the academic domain two studies (Vallerand \& Bissonnette, 1992; Vallerand et al., 1997) investigated the problem of drop-out using some of the elements of the HMIEM model. In a first study, Vallerand and Bissonnette (1992) conducted a prospective study with 1042 college students to determine the predictive effects of different forms of academic motivation (measured at Time 1 - in September) on behavioural persistence in a course (measured at Time 2 - in January). They found that students who had persisted in the course had previously reported higher levels of selfdetermined forms of regulation (intrinsic, identified regulation) and lower levels of non self-determined types of regulation (external, amotivated) than students who had dropped out. In the second study, Vallerand et al. (1997) tested a motivational model of high school dropout using a one-year prospective design, with 4,537 students. They found that the less autonomy supportive the teachers', parents' and school administration's behaviour, the less positive were students' perceptions of competence and autonomy. In turn, negative perceptions of autonomy and competence led to low levels of self-determined school motivation which translated into intentions to drop out of high school, and later on, to actual dropout behaviour.

In the sport domain, only one study to our knowledge tested dropout from the current perspective. Using a prospective 3 wave design, Pelletier et al. (in revision) found support for some elements of the causal sequence proposed by Vallerand (1997). Specifically, perceptions of coaches' controlling interpersonal behaviour facilitated higher levels of non self-determined types of regulation while autonomy-supportive 
coaching behaviour was associated to higher levels of self-determined motivation. Moreover, self-determined types of motivation at Time 1 were associated to higher levels of persistence at both Time 2 (10 months later) and Time 3 (22 months later) while the opposite took place for the non self-determined forms of motivation at both Time 2 and Time 3 . However, this study did not assess athletes' perceptions of competence, autonomy, and relatedness nor their intentions of dropping out. The Present Study

This study pursued two main goals. The first was to test the 4-stage causal sequence proposed by the HMIEM (Vallerand, 1997), to explain the dropout phenomenon in female handball. Although several studies from the motivational literature support the different parts of the sequence, no study so far has tested the model in its entirety. This applies to the three studies on dropout. Although they all included the more or less selfdetermined form of motivation and the motivational consequences, the social determinants (Vallerand \& Bissonnette, 1992) and certain mediators like relatedness (Vallerand et al., 1997) or even the three mediators altogether (Pelletier et al., in revision; Vallerand \& Bissonnette, 1992) were not ascertained. The present study, therefore, provides a more thorough test of the causal sequence involving all elements while using a 21-month prospective design and structural equation modelling (SEM). Overall, we believe that the present study should allow us to better understand the psychological processes involved in dropping out of sport as well as provide a test of intrinsic-extrinsic motivation theory and research, which underlies the motivational model.

The second purpose of this study was to integrate elements of the Hierarchical Model with achievement goal theory. Few empirical examinations have been conducted 
integrating the two conceptual models. There is some research that has examined connections between achievement goals and intrinsic motivation (assessed by the IMI or the interest/satisfaction scale; see above). Nevertheless, as Duda \& Hall (2000) have proposed, to have a comprehensive understanding of the motivational processes involved, it is necessary to go beyond these simple associations and to consider how intrinsic and extrinsic facets of motivation and perceptions mediate the relationship involving perceived climate and behavioural outcome. The rare studies conducted so far (e.g., Biddle, Soos, \& Chatzisarantis, 1999; Brunel, 1999) reveal that a task-involving climate (and/or orientation) predicts self-determined forms of motivation (intrinsic motivation and identified regulation) while ego-involving climate (and/or orientation) predicts non self-determined forms of motivation (amotivation and external regulation).

In the present study, it was hypothesised that the social context would influence athletes' perceptions of competence, relatedness, and autonomy. Specifically, the more ego-involving the motivational climate instilled by the coach, the less positive athletes' perceptions of competence, relatedness, and autonomy were expected to be. By contrast, the more task-involving the climate, the more positive such perceptions should be. In turn, perceptions of competence, relatedness, and autonomy were expected to be positively associated with self-determined motivation towards handball. Finally, low levels of self-determined motivation were expected to lead to the development of intentions to eventually drop out of handball. Research in the attitude literature reveals that intentions represent a proximal predictor of behaviour (Ajzen \& Fishbein, 1980; Ajzen, 1985, 1996; Eagly \& Chaiken, 1993), particularly in the field of leisure (e.g., Ajzen \& Driver, 1992) and exercise (e.g., Fortier \& Grenier, 1999; Kimiecik, 1992). 
Consequently, intentions to quit handball were expected to lead to actual dropout behaviour, and to mediate the effect of behavioural regulations on actual behaviour.

Method

\section{Participants}

Participants were 335 French handball females between the ages of 13 and 15 years $(\underline{M}=14.07$ years, $\underline{\mathrm{SD}}=0.79$ years $)$. These athletes came from 53 different teams from a French league. They were ranked at the regional level and were training an average of four hours a week.

\section{Questionnaire}

The questionnaire was made up of five parts. In the first part of the questionnaire, participants indicated their date of birth, years of handball experience, competition level and their number of hours of training per week. Following parts of the questionnaire assessed (1) the motivation of the players for handball, (2) perceptions of motivational climate emphasised by the coach, ${ }^{1}$ (3) motivational mediators, and (4) future sport intentions. Participants were asked to indicate to what extent they agree or disagree with each item by using a 7-point answer format, anchored by strongly disagree (1) and strongly agree (7). All summary scores were calculated by averaging the items within a scale (with negative items reverse coded).

The Sport Motivation Scale. Players completed the French version of the Sport Motivation Scale (SMS; Pelletier, Vallerand, Fortier, Tuson, Brière, \& Blais, 1995) namely "L'Échelle de Motivation dans les Sports" (EMS; Brière, Vallerand, Blais \& Pelletier, 1995), which assesses participants' motivation toward the sport. In the SMS and EMS, athletes are asked "Why do you practice your sport". They are provided with 28 items presented in the form of answers to that question. These items assess the 
constructs of amotivation, three types of extrinsic motivation (external, introjected, identified regulation), and three types of intrinsic motivation (to know, toward accomplishments, to experience stimulation). Recent studies (see Vallerand \& Fortier, 1998, Vallerand \& Losier, 1999, for a review) confirmed the factor structure of the scale and revealed satisfactory level of internal consistency as well as adequate test-retest reliability. In the present study, Cronbach alphas of the seven subscales ranged from .68 to .83 . Subscales can be used separately or in combination to form a summary score called the self-determination index (Grolnick \& Ryan,1987; Ryan \& Connel1, 1989; Vallerand, 1997).

\section{Perceived motivational climate emphasised by the coach. Participants} completed the modified French version of the Perceived Motivational Climate in Sport Questionnaire (PMCSQ), namely 'L'Échelle de Perception du Climat Motivationnel' (EPCM; Biddle, Cury, Goudas, Sarrazin, Famose \& Durand, 1995; Cury, Biddle, Famose, Goudas, Sarrazin \& Durand, 1996). The PMCSQ is a scale developed by Duda and colleagues (e.g., Duda \& Whitehead, 1998; Seifriz, Duda, \& Chi, 1992; Walling, Duda, \& Chi, 1993) to assess players' perceptions of the degree to which their teams' motivational climates were characterised by an emphasis on task- or ego- goals. Specifically, the French version of the PMCSQ is a 18 -item questionnaire hierarchically ordered to assess the perceived motivational climate in terms of two higher order factors, namely Task- and Ego-involving climate, and five lower order factors, two assessing the task-involving climate, and three the ego-involving nature of the achievement context. Task-involving dimensions consist of items reflecting an emphasis on 'promotion of learning by coach' (e.g., "The coach encourages you to work on weaknesses ") and 'pursuit of progress by athletes' (e.g., "Players try to learn new skills 
"). Ego-involving dimensions consist of items reflecting an emphasis on 'pursuit of comparison by athletes' (e.g., "Players feel good when they do better than teammates"), 'worries about mistakes' (e.g., "Players are afraid to make mistakes") and 'limited recognition' (e.g., "The coach pays most attention to the stars"). When completing the EPCM, the athletes were asked to respond by making reference to what it was like playing on their particular teams over the course of the season. In previous research, this scale has been found to be valid and reliable (Biddle et al., 1995; Cury et al., 1996). For the purposes of the present study, the two higher order factors of the EPCM (namely Task- and Ego-involving climate) were utilised in all subsequent analyses (Cronbach alpha coefficients for task and Ego involving climate subscales were .84 and .75 , respectively).

Motivational mediators. To assess perceived handball competence, a 4-item questionnaire (e.g., "I consider myself to be a good player") adapted from the Perceived Competence in Life Domains Scale (PCLDS, Losier, Vallerand, \& Blais, 1993) was used. PCLDS assesses perceptions of competence toward various life domains, including education and leisure, and has been found to be highly reliable and valid. In this study, the Cronbach alpha coefficient was .80 .

To assess the participants' feeling of autonomy in handball environment, a 3item questionnaire (e.g., "I feel controlled at handball"; this scale used reverse scoring) adapted from the Perceived Autonomy Toward Life Domains Scale (PALDS, Blais, Vallerand, \& Lachance, 1990, unpublished manuscript, University of Quebec at Montreal) was used. PALDS assesses one's perceptions of autonomy in different life domains, including education and leisure, and has been found to be reliable and valid. In this study, the Cronbach alpha coefficient was $.58 .^{2}$ 
To assess perceived handball relatedness, a 4-item questionnaire (e.g., "I feel attached to the girls on my team") adapted from the Feelings of Relatedness Scale (FRS; Richer \& Vallerand, 1998) was used. The FRS assesses one's perceptions of relatedness in the work place, and has been found to be reliable and valid. In this study, the Cronbach alpha coefficient was .91.

Future sport intentions. In the fifth part of the questionnaire, participants were asked to complete four items (based on the work of Ajzen \& Driver, 1992) that measured their future sport intentions (e.g., "I often consider dropping out of handball", reverse scoring). This subscale was found to possess adequate internal consistency $(\alpha=$ $.88)$.

Procedure.

The handball competitive year in France usually starts at the beginning of September and finishes at the end of June. Towards the middle of the season (in February 1998), the questionnaire was sent to the 62513 to 15 -year old players of a French handball league. A postage-paid reply envelope was also provided. A letter accompanying the questionnaire explained that the purpose of the study was to know more about why girls played handball and how they reacted to this sporting experiment. It was clearly stated to participants that anonymity and confidentiality of their answers would prevail at all times. Three hundred and thirty five questionnaires were returned (for a $54 \%$ return rate). The major dependent variable was dropping out of handball. This was defined as the non-re-registration of an athlete for the sport of handball after the beginning of the season, whatever the reason. Thus, twenty-one months later, i.e. after the beginning of the 1999/2000 season, the French Federation of Handball was contacted in order to establish a list of players registered for the year. People who did 
not re-register were contacted by phone to ensure that they did not practise the activity any more. Throughout these procedures, a total of 74 drop-out cases was identified (for a $22 \%$ dropout rate).

\section{Results}

Two sets of analyses were carried out. The first set focused on the differences between drop-out and persistent athletes on the different subscale means. The second set of analyses tested the 4-stage causal sequence proposed by the HMIEM (Vallerand, 1997). Our primary method of analysis was SEM (LISREL 8; Jöreskog \& Sörbom, 1996). This method, which is particularly useful in longitudinal research (Bentler, 1980), allows examination among all the constructs involved in a model using a latent representation of constructs that is not influenced by errors of measurement.

Motivation Toward Sport and Behavioural Intentions

A 2 (player status: dropout vs. persistent) $\times 7$ (type of sport motivation) analysis of variance (ANOVA) with repeated measures on the motivation variable was performed on the data. This design allows one to test for the presence of a Type of player $\mathrm{x}$ Motivation interaction, in which dropout athletes are expected to score lower than persistent players on self-determined forms of motivation (i.e., intrinsic motivation and identified regulation) but higher on non-self-determined types of motivation (especially amotivation). It should be noted that to correct for positively biased $\underline{F}$ tests due to repeated measures (Kirk, 1984), we used the Greenhouse-Geisser formula. Results revealed a significant main effect for sport motivation, $\underline{\mathrm{F}}(6,1998)=426.89, \underline{\mathrm{p}}<$ .0001 . Neuwman-Keuls post hoc analyses revealed that the seven motivational subscales were significantly different from one another. The most important forms of motivation for participants in this sample, in decreasing order, intrinsic stimulation ( $\underline{M}$ 
=5.36), intrinsic accomplishment $(\underline{\mathrm{M}}=5.19)$, intrinsic knowledge $(\underline{\mathrm{M}}=5.02)$, identified regulation $(\underline{M}=4.35)$, introjected regulation $(\underline{M}=4.16)$, external regulation $(\underline{\mathrm{M}}=2.59)$, and amotivation $(\underline{\mathrm{M}}=1.53)$. Of greater interest, results also revealed a significant Status of player x Motivation interaction, $\underline{F}(6,1998)=4.36, \underline{p}<.001$. Simple effect analyses indicated that four of the seven motivational subscales yielded significant differences between the two types of players (see Table 1). Results showed that 21 months before (at Time 1), dropout players were significantly less intrinsically motivated to know, to accomplish, and to experience stimulation and displayed more amotivation than persistent players. No differences were found between the two types of players on identified regulation, introjected regulation and external regulation. The means and standard deviations of the motivational subscales as a function of status of player appear in Table 1.

With respect to behavioural intentions, results revealed a main effect for status of player, $\underline{F}(1,333)=102.67, \underline{p}<.0001$. Players who dropped out had greater intentions to drop out of handball than did those who persisted. ${ }^{3}$

Insert Table 1 here

Perceived Handball Competence, Autonomy, and Relatedness

A multivariate analysis of variance (MANOVA) was conducted to determine whether there were significant differences on perceptions of competence, autonomy, and relatedness as a function of players. Results revealed a significant multivariate main effect for the type of player, Wilk's lambda $=.92$, Rao's $\underline{\mathrm{R}}(3,331)=10.05, \underline{\mathrm{p}}<.0001$. Follow-up univariate analyses of variance (ANOVAS) revealed significant differences 
between dropout and persistent players for all three variables (see Table 2). Dropout players perceived themselves as significantly less competent, autonomous and related to their team than persistent players. The means and standard deviations of the motivational mediator subscales as a function of status of players appear in Table 2 .

Insert Table 2 here

\section{Perceived Motivational Climate Emphasised by the Coach}

A MANOVA was conducted to determine whether there were significant differences on perceptions of motivational climate emphasised by the coach as a function of players. Results revealed a significant multivariate main effect for the status of player, Wilk's lambda $=.98, \underline{\mathrm{R}}(2,332)=3.96, \underline{\mathrm{p}}<.05$. Follow-up univariate ANOVAS revealed significant differences between dropout and persistent players for the task-involving climate (see Table 2). Dropout players perceived motivational climate emphasised by the coach as significantly less task-involving than persistent players. A reverse trend can also be observed for the ego-involving climate $(\mathrm{p}<.10)$ : dropout players perceived motivational climate emphasised by the coach as significantly more ego-involving than persistent players. The means and standard deviations of the perceived motivational climate subscales as a function of type of players appear in Table 2.

\section{Test of the 4-Stage Causal Sequence}

We tested Vallerand's 4-stage causal sequence using SEM. In light of the already high number of variables in the model, we decided to reduce this one and hence keep the model' degrees of freedom reasonable. First of all, the items of each construct were measured by two random aggregates of items (Bagozzi \& Heatherton, 1994; 
Bentler, 1980; Byrne, 1994; MacCallum \& Austin, 2000). For instance, the 4 items of perceived competence were grouped in two 2-item averaged scores via random splitting of the scale, whereas the 9 items of the mastery dimension of the climate were grouped in two random aggregates of respectively 5 and 4 items each.

Finally, we decided to use the self-determination index (SDI). This index rests on the existence of a quasi-simplex (ordered correlation) pattern between the seven subscales of motivation (e.g., Li \& Harmer, 1996). The SDI was calculated by giving each subscale a specific weight according to its respective place on the selfdetermination continuum, multiplying this weight by the score of the subscale, and adding the scores of all subscales to derive a single score. Thus, the scores for the three types of intrinsic motivation were averaged and assigned the highest positive weight $(+2)$ because intrinsic motivation is the highest self-determined form of motivation. Identified extrinsic motivation, a self-determined type of extrinsic motivation, was assigned a lower weight $(+1)$. The scores for external regulation and introjection were averaged and assigned a negative weight (-1), and amotivation, which represents the absence of self-determination, was weighted highly negatively (-2). Support for the validity and reliability of this type of composite index has been obtained in several studies (see Ryan \& Connell, 1989; Vallerand, 1997; Vallerand \& Fortier, 1998; Vallerand \& Losier, 1999). Within the framework of this study, latent variables assessing self-determined handball motivation, consisted of two composite indexes (because the number of items of each subscale was aggregated to form two 2-item averaged scores).

To test predicted relations between the variables, we adopted Anderson and Gerbing's (1988) two-step modelling approach intended to identify better the sources of 
poor overall model fit. The first step (the measurement model) corresponds with a confirmatory factor analysis (CFA) and allows researchers to focus on the factor structure underlying the two composite scores of each construct. This first analysis also allows us to test the discriminant validity of factors sharing a common method (e.g., self-report), which would tend to inflate correlations between the measures across constructs (see Perugini \& Conner, 2000). Then, the second step (structural model) consists of testing simultaneously the structural and measurement models and allows us to focus on conceptual connections among the latent factors and actual dropout behaviour.

Step 1: Measurement model. The CFA model was based on 14 observed measures (the composite scores) and 7 latent constructs (see Figure 1). As recommended by Anderson and Gerbin (1988), the latent factors were allowed to correlate freely during assessment of the measurement submodel.

Since the variables were highly abnormal (tests of zero multivariate skewness $=$ $34.05, \underline{p}<.0001$ and zero multivariate kurtosis $=13.63, \underline{p}<.0001)$, PRELIS 2 (Jöreskog \& Sörbom, 1993), a preprocessor of LISREL, was used to generate the polychoric correlation and its corresponding asymptotic covariance matrix (Jöreskog, 1990). Both matrices were used as input for the LISREL 8 program (Jöreskog \& Sörbom, 1996) and analysed by the Generally Weighted Least Squares (WLS) method of estimate as it is more robust to deviations from normality compared with the maximum likelihood method (Bollen, 1989; Jöreskog, 1990; Jöreskog \& Sörbom, 1996). ${ }^{4}$

In view of the current state of controversy regarding measure of overall goodness of fit, it is generally recommended to report multiple indices (Bollen, 1989). Based on the suggestions made by several people (Bentler, 1990; Bollen \& Long, 1993; 
McDonald \& Marsh, 1990; Mulaik, James, Van Alstine, Bennett, Lind, \& Stilwell, 1989) the following fit indexes were used to evaluate the adequacy of the measurement model: the chi-square statistic, the goodness-of-fit index (GFI; Jöreskog and Sörbom, 1996), the normed fit index (NFI; Bentler \& Bonett, 1980), the comparative fit index (CFI; Bentler, 1990), and the root mean square residual (RMSR; Jöreskog \& Sörbom, 1996).

The measurement model provided an adequate fit to the data, $\chi^{2}(56, \underline{N}=335)=$ $68.61, \underline{p}>.10, \mathrm{GFI}=1.00 ; \mathrm{NFI}=1.00 ; \mathrm{CFI}=1.00 ; \mathrm{RMSR}=.04$. All $\underline{\lambda}$ were significant $(\mathrm{t}>2.00)$. Because the fit indices were very high, it was deemed appropriate to comment on the RMSR. The RMSR is a measure of the average residuals between the implied and observed covariances. Values less than 0.10 are interpreted as indicating a good fit to the data (Rupp \& Segal, 1989). The correlations between latent constructs, disattenuated for measurement error, were inspected to verify the discriminant validity between the constructs. The correlations were moderate to null, except for the estimated correlation between perceived autonomy and self-determined motivation $(\phi=0.71)$, between perceived autonomy and behavioural intention $(\phi=-0.69)$, and between selfdetermined motivation and behavioural intention $(\phi=-0.62)$. However, the confidence intervals ( \pm two standard errors) for these disattenuated correlations supported the discriminant validity for these constructs, insofar as none of the interval included 1.0 (Anderson \& Gerbing, 1988). ${ }^{5}$ Standardised estimates, residuals variances, interfactor correlations, and standard errors for the measurement model are displayed in Figure 1. Thus, results from the confirmatory factor analysis revealed that the measurement model was appropriate. 
Insert Figure 1 here

Step 2: Structural model. After having assessed the adequacy of the factor structure, we could now focus on the hypothesised relations among the seven latent dimensions and actual dropout behaviour assessed through a dichotomous variable $(0=$ re-enrolled; 1 = dropped out).

Insert Figure 2 here

The structural and measurement coefficients of the hypothesised model are displayed in Figure 2. With the exception of the chi-square statistics which is strongly influenced by sample size, $\chi^{2}(79, \underline{N}=335)=203.74, \underline{p}<.001$, other goodness-of-fit indices revealed that the model adequately reflected the data $(\mathrm{GFI}=.99 ; \mathrm{NFI}=.99 ; \mathrm{CFI}$ $=.99 ; \mathrm{RMSR}=.088)$. All estimated parameters were significant $(\mathrm{t}>2.00)$ except for the direct effect of Ego-involving climate on perceived competence and relatedness. Therefore, the structural paths between these variables were deleted and do not appear in Figure 2. As suggested by Duda (2001), task- and ego-involving climates were negatively and moderately related, suggesting that the two constructs were perceived as being relatively independent. In line with the proposed model, the more the players perceived that the motivational climate of the coach emphasised learning process, investment, and progress (i.e., task-involving), the more autonomous ( $\underline{\beta}=0.51)$, related $(\underline{\beta}=0.56)$, and competent $(\underline{\beta}=0.27)$ they felt. By contrast, the more the players perceived that the motivational climate was ego-involved, the less autonomous ( $\underline{\beta}=-$ $0.24)$ they felt. In turn, the more autonomous $(\beta=0.78)$, competent $(\beta=0.23)$, and 
related $(\underline{\beta}=0.08)$ players felt, the more self-determined was their handball motivation. Low levels of self-determined motivation $(\underline{\beta}=0.79)$ were associated with intentions to drop-out, which in turn, predicted actual drop out behaviour 21 months later $(\underline{\beta}=$ $0.55)^{6}$

\section{Discussion}

Adolescents, especially females, have been identified as a group at risk of poor health due to their declining level of physical activity (Gould, 1987; Russell, et al., 1996; Sallis \& Patrick, 1996; Wankel \& Mummery, 1996). Approximately 35\% of those involved in youth sport discontinue involvement each year (Gould, 1987). Frenchwoman handball players are no exception to the rule, because approximately $50 \%$ dropout between the age of 13 and 15 (Guillet \& Sarrazin, 1999). Even if the withdrawal from a sport, does not prevent adolescents from participating in other types of physical activity (Gould, 1987), research is needed on the nature of the factors that facilitate attrition in sport and physical activity programs. Precisely, the purpose of this study was to test a motivational model of sport dropout that integrates the 4 stagecausal sequence proposed by the Hierarchical Model of Vallerand (1997) and elements from achievement goal theory (Nicholls, 1989) in order to explain the phenomenon of withdrawal in female handball, using a 21-month prospective design and SEM. This model posits that the coach's behaviour toward female handball influences athletes' perceptions of competence, relatedness, and autonomy. In particular, the more egoinvolving the coach's behaviour, the less positive females' handball perceptions. Conversely, the more task-involving the coach's behaviour, the more positive females' handball perceptions. In turn, the less positive athletes' perceptions of competence, relatedness, and autonomy, the lower their levels of self-determined motivation. Finally, 
low levels of self-determined motivation are expected to lead students to develop intentions to drop out of handball, which are later acted out. The present results provide strong support for the proposed model and lead to implications with respect to both consequences and determinants of motivation.

\section{On the Motivational Consequences}

First, results revealed that dropout female handballers had lower levels of intrinsic motivation (toward knowledge, accomplishment and experiencing stimulation), but higher levels of amotivation than persistent players. By contrast, the various types of extrinsic motivation were neither predictive of sport dropout intentions nor related to actual behaviour. Moreover, results of SEM supported the hypotheses that the lack of self-determined motivation leads to dropping out of sport. On the whole, these results corroborate the former results obtained with respect to dropout in school (Vallerand \& Bissonnette, 1992; Vallerand et al., 1997), exercise (Fortier \& Grenier, 1999; Ryan, Frederick, Lepes, Rubio \& Sheldon, 1997), and sport settings (Pelletier et al., in revision). More generally, these results are in agreement with much field research over the past two decades which showed that the self-determined motivation lead to a host of positive outcomes (see, Vallerand, 1997, for a review). These findings are also in conformity with descriptive studies on motives for participating in sport which show that factors related to intrinsic motivation such as the desire to learn and improve skills, to have fun, and to play for the challenge that the game provides are consistently among the top reasons cited for sport involvement (see Gould, 1987; Weiss \& Chaumeton, 1992, for reviews). Thus, it seems that the main reasons explaining girls' involvement in handball are intrinsic rewards. When they don't derive such benefits from their participation, they stop participating. 
The results of this study also suggest that the impact of motivation on behaviour is not direct but is fully mediated by behavioural intentions. Some contemporary socialcognitive theories (e.g., Ajzen, 1985, 1996; Ajzen \& Fishbein, 1980; Gollwitzer, 1990; Heckhausen, 1991; Perugini \& Conner, 2000) and accumulated evidence indicate that intentions represent a proximal predictor of behaviour in leisure (e.g., Ajzen \& Driver, 1992), exercise (e.g., Biddle et al., 1999; Fortier \& Grenier, 1999; Kimiecik, 1992; see Hausenblas, Carron \& Mack, 1997, for a review), and other activities (e.g., Randall \& Wolff, 1994; Sheppard, Hartwick \& Warshaw, 1988), whereas goals represent more distal determinants of behaviour (e.g., Eagly \& Chaiken, 1993; Perugini \& Conner, 2000; Vallerand, Fortier, \& Guay, 1997). However, it should be kept in mind that other factors are likely to be involved in the dropout process such as attractiveness of other leisure activities and/or perceptions of work, study or family duties (see Guillet, Sarrazin, Carpenter, Trouilloud \& Cury, in revision; Lindner, Johns \& Butcher, 1991; Sarrazin \& Guillet, 2001; Weiss \& Chaumeton, 1992). Future research is needed in order to determine how these other factors may be best integrated in the motivational model proposed in the present study.

Of interest is that in this study self-determined motivation predicted $62 \%$ of the variance in behavioural intentions of dropping out, which predicted themselves $31 \%$ of the variance in the actual behaviour. There are at least two main explanations to the fact that the link between intentions and behaviour was only of moderate magnitude. The first is that behaviour was not totally controlled by the athletes (Ajzen, 1985). In some cases, the withdrawal was externally controlled (Gould, 1987). For example, athletes who are cut from teams, or who suffer from such severe injuries that they are no longer able to participate have no choice but to withdraw from the activity. It is thus possible 
that 21 month earlier some athletes did not express a desire to leave the activity but nevertheless did due to factors outside of their control (e.g., an injury). Future studies should check if the final decision of dropping out was under the athletes' control or not. Another potential explanation for the fact that the link between intention and behaviour was moderate is that intention were measured 21 months before behaviour. It is possible that intentions changed over this long period because individuals are more likely to be exposed to new information and thus to change their intentions (Ajzen, 1985). Future studies should analyse the stability of intentions and more generally determine the boundary conditions of the intentions-behaviour link (Ajzen, 1985; Ajzen \& Fishbein, 1980) in order to better predict dropout behaviour.

Contrary to previous research (e.g., Chatzisarantis et al., 1997; Sheeran et al., 1999) there was no evidence for the moderating effect of self-determined motivation on the intention-behaviour relationship. Indeed, in these studies intentions based on autonomous forms of regulation better predicted behaviour than intentions based on controlling forms of regulation, probably because the second are less stable (with controlling forms of regulation individuals are expected to keep engaging in tasks as long as external controls are in effect; when controls are withdrawn, their effect on motivation disappear, thus causing changes in motivation). In the present research, the absence of a moderating effect suggests that this reasoning is perhaps less relevant when the activity is sought for fun and as an opportunity to be free from extrinsic pressures, as it is the case for elective/leisure-time activities (as handball in this study). Contrary to exercise and fitness behaviours (as in Chatzisarantis et al., and Sheeran et al., studies) where motivations are more extrinsic (e.g., Biddle et al., 1999; Chatzisarantis et al., 1997; Fortier \& Grenier, 1999; Ryan et al., 1997) with elective/leisure-time activities an 
individual who does not experience pleasure or who feels constrained will probably quickly decide to drop out from the activity (see Deci \& Ryan, 1985). Close inspection of our data shows indeed that very few players decided to continue (i.e., weak intention to drop out) when they had a low self-determined motivation. Additional research is necessary to test the hypothesis according to which the moderating effect of selfdetermined motivation on the intention-behaviour relationship depends on the type of activity (exercise behaviours and fitness programs versus recreational behaviours). On the Social Determinants of Motivation

The findings from this study corroborate the role of the social context (and more particularly the influence of the coach) as a source of influence on motivation. As expected, dropout female handballers perceived (1) their coach as being less taskinvolving, and more ego-involving (at $\mathrm{p}<10$ ) and (2) perceived themselves as being less competent, related and autonomous, than persistent players. Three points must be made in this respect.

First, in line with the Hierarchical Model (Vallerand, 1997; Vallerand \& Ratelle, in press), results of SEM showed that the impact of the social context (i.e., the climate) on motivation was mediated by the individual's perceptions of competence, autonomy, and relatedness. These three perceptions explained $78 \%$ of the variance in selfdetermined motivation toward handball. Thus, coaches' behaviour will influence athletes' motivation only in cases in which they affect the athletes' perceptions of competence, autonomy and relatedness. Although some support has been found for the mediational role of perceptions of competence (e.g., Biddle et al., 1999; Blanchard \& Vallerand, 1996; Cury et al., 1996; Reeve \& Deci, 1996; Vallerand et al., 1997), autonomy (e.g., Blanchard \& Vallerand, 1996; Reeve \& Deci, 1996; Vallerand et al., 
1997), and relatedness (Blanchard \& Vallerand, 1996) on intrinsic motivation, most research has focused on the direct influence of social agents (e.g., teachers, coaches, and parents) on individual's motivation or has assessed the link between social agents' behaviours and individual's perceptions without testing the link between perceptions and motivation. This study is one of the first to provide support for the mediating role of the three perceptions of competence, autonomy, and relatedness on self-determined motivation.

A second, related point deals with the relative impact of social-contextengendered perceptions of competence, autonomy and relatedness on motivation. ${ }^{7}$ Very little research has concerned this issue. In accordance with some former studies (e.g., Reeve \& Deci, 1996; Vallerand et al., 1997) the results of the present study indicated that the path from perceived autonomy to self-determined motivation $(\underline{\beta}=.78)$ was significantly stronger than the one from perceived competence to self-determined motivation $(\underline{\beta}=.23)$. In addition, the results showed that the path from perceived relatedness to self-determined motivation $(\underline{\beta}=.08)$ was significantly weaker than the two others. These results are in conformity with self-determination theory (Deci \& Ryan, 2000) which suggests that the need for autonomy represents a most fundamental need than the others (competence and relatedness). In addition, these findings support Deci and Ryan's contention, relatedness plays a more distal role in the maintenance of intrinsic motivation. Nevertheless, it is also possible that the relative weight of these three influences depends on the nature of the task, the conditions in which activities are performed, and the individual's needs (Vallerand, 1997). Future research is needed to understand better the relative impact of perceived autonomy, competence and relatedness on motivation. 
A third and final point with respect to the impact of the social context on motivation refers to the type of behaviour of the social agent which is taken into account. The majority of the studies in the area have focused on the distinction between the support of autonomy and the control of behaviour (e.g., Deci \& Ryan, 1987; Pelletier et al., in revision). An important purpose of this study was to assess how another type of coaching behaviour (the concept of motivational climate instilled by coaches and taken from Achievement Goal Theory) related to perceptions of competence, autonomy, and relatedness and self-determined motivation (taken from Self-Determination Theory and the HMIEM). Research in sport and exercise using the AGT perspective has shown that generally higher levels of task involvement are associated with higher levels of intrinsic motivation that is experienced by athletes, because the latter engage in an activity for its own sake and thus, consider it to be an end in itself (Nicholls, 1989). By contrast, the more ego-involvement is encouraged, the less intrinsic motivation is experienced, because (1) the activity is only a means to an end (Nicholls, 1989), (2) athletes' actions then have an external perceived locus of causality (successful outcomes depend mainly on what the opponent does), and (3) a feeling of anxiety (see, Duda \& Hall, 2000, for a review) and of pressure to maintain self-esteem is experienced (Ryan \& Deci, 2000). These correlational studies are in agreement with a number of laboratory experiments (e.g., Butler, 1988; Harackiewicz et al., 1987; Ryan, 1982; Ryan et al., 1991; Vallerand et al., 1986) which show that egoinvolving manipulations lead to significantly lower levels of intrinsic motivation and enjoyment than task-involving inductions.

As mentioned above, there are very few studies that tested the potential mediators of perceptions of competence, autonomy and relatedness, between 
achievement climate and self-determined motivation. The results of the present study revealed that the more players perceived that the motivational climate was taskinvolving, the more competent they felt $(\beta=.27)$, presumably because this type of climate highlights athletes' progress and effort, and thus maximises the opportunities to feel more competent-- a result consistent with past research (e.g., Cury et al., 1996). In addition, the more players perceived that the motivational climate was task-involving, the more related they felt $(\beta=.56)$, probably because an important aspect of this climate is to emphasise team member cooperation and to foster a sense that everyone on the team plays an important role (Duda, 2001). Lastly, task-involving climate also predicted perceived autonomy $(\underline{\beta}=.51)$. This is an interesting result because it shows that a task-involving climate tends to support the autonomy of the players. By contrast, an ego-involving climate predicted low perceived autonomy $(\underline{\beta}=-.24)--$ a result consistent with experimental research on the effects of the competition (e.g., Reeve \& Deci, 1996). On the other hand, an ego-involving climate was found to be unrelated to either perceived competence or relatedness perhaps because the competitive outcome (i.e., number of victory) constitutes a moderator in such a relationship. Indeed, one can suppose that a player who interacts in an ego-involving climate will feel competent and related as long as the team wins. However, these perceptions are likely to dramatically decrease if the team regularly loses. Future research should test the validity of this hypothesis.

In sum, the present findings provide strong support for the 4-stage causal sequence of the Hierarchical Model of Vallerand (1997) as applied to the sport dropout issue. In addition, it reveals that integrating Achievement Goal Theory and the 
Hierarchical Model represents a promising new line of research which would deserve further scientific scrutiny (to this effect, see Duda \& Hall, 2000).

Limitations

Although the present results provided support for the proposed model, some limitations should be acknowledged and kept in mind when interpreting the findings. First and foremost, with the exception of dropout behaviour, the assessed variables are self-report data. Thus, this should create some shared error variance among the model variables and cast some doubts on the present results. However, as mentioned earlier, the results of this study are directly in line with those of laboratory experiments on the determinants of motivation where participants were randomly assigned to conditions (thus controlling for individual differences and systematic error). Therefore, although it is possible that the self-report measures used in this study induced some shared variance in the model, we nevertheless feel confident about the validity of the present results. In line with the preceding point, a second limitation of this study is that it did not include an objective measure of the coach climate. Although past research (e.g., Pelletier \& Vallerand, 1996; Smith et al., 1979) has shown that children's perceptions of adults in authority positions are highly consistent with adults' perceptions of their own behaviour, as well as with that of independent judges' perceptions, future work should certainly include non-player-based assessments of the context to explore more fully what contributes to the athletes' perceptions of the social context.

A third limitation pertains to the fact that this study was limited to a linear modelling analysis using player-level data. So there is a hidden nesting to the data structure and teams most likely introduce nonindependence of observations. Consequently, Hierarchical Linear Modelling (HLM) would have been the most 
appropriate method of analysis. However, because of the small number of players in many of the teams (41 teams had less than 8 players) and the complexity of our model, HLM was discarded. ${ }^{8}$ Nevertheless, additional studies with larger samples and more players per team using two-level hierarchical designs should allow us to determine the level of interplay between the individual and the team as a whole. A final limitation is that this study was limited to adolescent girls playing handball at a low level of competition. The extent to which these results generalise to male handballers, to elite athletes, and more generally to other types of sport and exercise, is unknown and should be empirically determined. However, in light of past findings on the dropout process where models similar to the present one were supported with male and female students (Vallerand et al., 1997) and with male and female swimmers (Pelletier et al., in revision) we are optimistic that future research should support the present model.

\section{On the Sport Dropout Issue}

Despite these important caveats, the present results have at least two important implications for the sport dropout issue. First, self-determined motivation is a key variable to consider when attempting to predict sport dropout. The present results showed that a lack of intrinsic motivation as well as a concomitant increase in amotivation, predicted behavioural intentions of dropping out. It thus appears that these two variables represent key motivational constructs in the understanding and prediction of sport dropout. Consequently, intrinsic motivation should be nurtured in order to facilitate athletes' persistence in sports.

A second implication is that the social context plays a fundamental role in the dropout process. The present findings showed that when the climate instilled by the coach was ego involving, perceptions of autonomy and in turn self-determined 
motivation decreased. However, when the climate was task involving, then perceptions of autonomy, competence, and relatedness and in turn self-determined motivation were enhanced. Such results may provide directions with respect to pertinent interventions to increase adherence in sport. In line with the proposed motivational sequence, it may be useful to educate the coaches on the impact of their behaviours on athletes' motivation in order to bring about changes in coaches behaviours, that in turn lead to positive changes in athletes' motivation and level of persistence (Vallerand \& Losier, 1999). A key element may be to encourage coaches to foster task-involving climates in order to help participants focus on the mastery dimensions of the activity and not on the extrinsic (i.e., winning at all costs) dimensions.

\section{References}

Abramson LY, Seligman ME, Teasdale JD. 1978. Learned helplessness in humans : Critique and reformulation. Journal of Abnormal Psychology 87: 49-74.

Aiken L, West S. 1991. Multiple regression: Testing and interpreting interactions; London: Sage.

Ajzen I. 1985. From intentions to actions: A theory of Planned Behaviour. In Actioncontrol: From Cognition to Behaviour, Kuhl J, Beckman J (eds); NY: Springer; 11-39.

Ajzen I. 1996. The directive influence of attitudes on behavior. In Psychology of Action, Gollwitzer PM, Bargh JA (eds); NY: Guilford ; 385-403.

Ajzen I, Driver BL 1992. Application of the theory of planned behaviour to leisure choice. Journal of Leisure Research 24: 207-224.

Ajzen I, Fishbein M. 1980. Understanding attitudes and predicting social behavior; Englewood Cliffs, NJ: Prentice-Hall. 
Ames C. 1992. Achievement goals, motivational climate, and motivational processes. In Motivation in sport and exercise, Roberts G (ed); Champaign, I1.: Human Kinetics Publishers; 161-176.

Anderson JC, Gerbin DW. 1988. Structural equation modeling in practice: A review and recommended two-step approach. Psychological Bulletin 103: 411-423.

Bagozzi RP, Heatherton TF. 1994. A general approach to representing multifaceted personality constructs: Application to state self-esteem. Structural Equation Modeling 133: $35-67$.

Baron RM, Kenny DA. 1986. The moderator-mediator variable distinction in social psychological research: Conceptual, strategic, and statistical consideration. Journal of Personality and Social Psychology 51: 1173-1182.

Bentler PM. 1980. Multivariate analysis with latent variables : Causal modeling. Annual Review of Psychology 31: 419-456.

Bentler PM. 1990. Comparative fit indexes in structural models. Psychological Bulletin 107: $238-246$.

Bentler PM, Bonett DG. 1980. Significance tests and goodness of fit in the analysis of covariance structure. Psychological Bulletin 88: 588-606.

Biddle S, Cury F, Goudas M, Sarrazin P, Famose JP, Durand M. 1995. Development of scales to measure perceived physical education class climate: a cross-national project. British Journal of Educational Psychology 65: 341-358.

Biddle S, Soos I, Chatzisarantis N. 1999. Predicting physical activity intentions using goal perspectives and self-determination theory approaches. European psychologist 4 : 83-89.

Bollen DA. 1989. Structural equations with latent variables; New York: Wiley. 
Bollen DA. Long JS. 1993. Testing structural equation models; Newbury Park, CA: Sage.

Brière NM, Vallerand RJ, Blais MR, Pelletier, LG. 1995. Développement et validation d'une mesure de motivation intrinsèque, extrinsèque et d'amotivation en contexte sportif: L'Echelle de Motivation dans les Sports (EMS). International Journal of Sport Psychology 26: 465-489.

Brunel PC. 1999. Relationship between achievement goal orientations and perceived motivational climate on intrinsic motivation. Scandinavian Journal of Medicine \& Science in Sports 9: 365-374.

Butler R. 1988. Enhancing and undermining intrinsic motivation: The effects of taskinvolving and ego-involving evaluation on interest and performance. British Journal of Educational Psychology 5: 1-14.

Byrne B. 1994. Structural Equation Modeling with EQS and EQS/Windows; Thousand Oks, California: Sage Publications.

Chatzisarantis NL, Biddle S. 1998. Functional significance of psychological variables that are included in the Theory of Planned Behaviour: A Self-Determination Theory approach to the study of attitudes, subjective norms, perceptions of control and intentions. European Journal of Social Psychology 28: 303-322.

Chatzisarantis NL, Biddle S, Meek GA. 1997. A self-determination theory approach to the study of intentions and the intention-behaviour relationship in children's physical activity. British Journal of Health Psychology 2: 343-360.

Cronbach LJ. 1951. Coefficient alpha and the internal structure of tests. Psychometrika 16: $297-334$. 
Connell JP, Wellborn JG. 1991. Competence, autonomy, and relatedness : A motivational analysis of self-system processes. In Self processes in development : Minnesota Symposium on Child Psychology, Gunnar MR, Sroufe LA (eds); Hillsdale, NJ : Erlbaum; 43-77.

Cury F, Biddle S, Famose JP, Goudas M, Sarrazin P, Durand M. 1996. Personal and situational factors influencing intrinsic interest of adolescent girls in school physical education : A structural equation modeling analysis. Educational Psychology 16: 305315.

Deci EL. 1971. Effect of externally mediated rewards on intrinsic motivation. Journal of Personality and Social Psychology 18: 105-115.

Deci EL, Ryan RM. 1985. Intrinsic motivation and self-determination in human behavior; New York: Plenum.

Deci EL, Ryan RM. 1987. The support of autonomy and the control of behaviour. Journal of Personality and Social Psychology 53: 1024-1037.

Deci EL, Ryan RM. 1991. A motivational approach to self : Integration in personality. In Nebraska symposium on motivation 1991 : Vol. 38. Perspective on motivation. Current theory and research in motivation, Dienstbier (ed); Lincoln, NE : University of Nebraska Press; 237-288.

Deci EL, Ryan RM. 2000. The "what" and "why" of goal pursuits: human needs and the Self-Determination of behaviour. Psychology Inquiry 11: 227-268.

Deci EL, Schwartz AJ, Sheinman L, Ryan RM. 1981. An instrument to assess adults' orientations toward control versus autonomy with children: Reflections on intrinsic motivation and competence. Journal of Educational Psychology 83: 642-650. 
Duda JL. 2001. Achievement goal research in sport: Pushing the boundaries and clarifying some misunderstandings. In Advances in motivation in sport and exercise, Roberts G (ed); Champaign, IL: Human Kinetics; 129-182.

Duda J, Hall H. 2000. Achievement goal theory in sport: Recent extensions and future directions. In Handbook of Sport Psychology ( $2^{\text {nd }}$ ed.), Singer R, Hausenblas H, Janelle C (eds); New York: John Wiley \& Sons, Inc; 417-443.

Duda JL, Nicholls JG. 1992. Dimension of achievement motivation in schoolwork and sport. Journal of Educational Psychology 6: 334-343.

Duda J, Whitehead J. 1998. Measurement of goal perspectives in the physical domain. In Advances in Sport and Exercise Psychology Measurement, Duda J (ed); Morgantown, WV: FIT; 21-48.

Dweck CS. 1986. Motivational processes affecting learning. American Psychologist 41: 1040-1048.

Eagly AH, Chaiken S. 1993. The Psychology of Attitudes. Harcourt Brace Jovanovich: Fort Worth, PA.

Ewing ME, Seefeldt V. 1996. Patterns of participation and attrition in American agency-sponsored youth sports. In Children in sport : A biopsychosocial perspective, Smoll FL, Smith RE (eds); Indianapolis : Brown \& Benchmark; 31-45.

Fortier M, Grenier M. 1999. Determinants personnels et situationnels de l'adhérence à 1'exercice: une étude prospective. STAPS 48: 25-37.

Fortier M, Vallerand RJ, Brière NM, Provencher PJ. 1995. Competitive and recreational sport structures and gender: A test of their relationship with sport motivation. International Journal of Sport Psychology 26: 24-39. 
Gollwitzer PM. 1990. Action phases and mind-sets. In Handbook of motivation and cognition: Foundations of social behavior, Higgins ET, Sorrentino RM (eds); New York: Guilford Press; 53-92.

Gottfried AE, Fleming JS, Gottfried AW. 1994. Role of parental motivational practices in children's academic intrinsic motivation and achievement. Journal of Personality and Social Psychology 86: 104-113.

Goudas M, Biddle S, Fox K, Underwood M. 1995. It ain't what you do, it's the way that you do it ! Teaching style affects children's motivation in track and field lessons. The Sport Psychologist 9: 254-264.

Gould D. 1987. Understanding attrition in children's sport. In Advances in pediatric sciences, Gould D, Weiss MR (eds); Champaign, I1: Human Kinetics; 61-85. Guillet E, Sarrazin P, Carpenter PJ, Trouilloud D, Cury F. In revision. Predicting persistence or withdrawal in female handballers with Social Exchange theory. International Journal of Psychology.

Harackiewicz JM, Abrahams S, Wageman R. 1987. Performance evaluation and intrinsic motivation: The effects of evaluative focus, rewards, and achievement orientation. Journal of Personality and Social Psychology 53: 1015-1023.

Hausenblas HA, Carron B, Mack D. 1997. Applications of the theories of reasoned action and planned behaviour to exercise behaviour: A meta-analysis. Journal of sport and exercise psychology 19: 36-51.

Heckhausen H. 1991. Motivation and action. Berlin: Springer-Verlag. Jöreskog K. 1990. New developments in LISREL : Analysis of ordinal variables using polychoric correlations and weighted least squares. Quality and Quantity 24: 387-404. Jöreskog K, Sörbom D. 1993. Prelis 2 : User's reference guide; Chicago : SSI Inc. 
Jöreskog K, Sörbom D. 1996. Lisrel 8 : User's reference guide; Chicago : SSI Inc. Kimiecik, J. (1992). Predicting vigorous physical activity of corporate employees: Comparing the theories of reasoned actions and planned behaviour. Journal of Sport and Exercise Psychology 14: 192-206.

Kirk RE. 1984. Elementary statistics (2nd ed.); Monterey, CA : Brooks/Cole.

Li F, Harmer P. 1996. Testing the simple assumption underlying the Sport Motivation Scale: A structural modeling analysis. Research Quarterly for Exercise and Sport 67: $396-405$

Lindner KJ, Johns DP, Butcher J. 1991. Factors in withdrawal from youth Sport : A proposed model. Journal of Sport Behavior 14: 4-18.

Losier GF, Vallerand RJ, Blais MR. 1993. Construction et validation de 1'Échelle des Perceptions de Compétence Dans les Domaines de Vie. Sciences et comportement 23: $1-16$.

MacCallum RC, Austin JT. 2000. Applications of structural equation modeling in psychological research. Anmual Review of Psychology 51: 201-226.

Madon S, Jussim L, Keiper S, Eccles J, Smith A, Palumbo P. 1998. The accuracy and power of sex, social class, and ethnic stereotypes: Naturalistic studies in person perception. Personality and Social Psychology Bulletin 24: 1304-1318.

McDonald RP, Marsh HW. 1990. Choosing a multivariate model: Noncentrality and goodness of fit. Psychological Bulletin 107: 247-255.

Martinsen EW. Stephens T. 1994. Exercise and mental health in clinical and freeliving populations. In Advances in exercise adherence, Dishman RK (ed); Champaing, IL : Human Kinetics; 52-72. 
Mulaik SA, James LR, Van Alstine J, Bennett N, Lind S, Stilwell CD. 1989. Evaluation of goodness-of-fit indices for structural equation models. Psychological Bulletin 105 : $430-445$.

Nicholls JG. 1989. The competitive ethos and democratic education; Cambridge, MA : Harvard University Press.

Ntoumanis N, Biddle SJ. 1999. A review of motivational climate in physical activity. Journal of Sports Sciences 17: 643-665.

Pedhazur EJ, Schmelkin LP. 1991. Measurement, design, and analysis : An integrated approach; Hillsdale, NJ : Erlbaum.

Pelletier LG, Fortier MS, Vallerand RJ, Brière NM. In revision. Associations between perceived autonomy support, forms of self-regulation, and persistence: A prospective study. Motivation and Emotion.

Pelletier LG, Fortier MS, Vallerand RJ, Tuson KM, Brière NM, Blais MR. 1995.

Toward a new measure of intrinsic motivation, extrinsic motivation and amotivation in sports: the Sport Motivation Scale (SMS). Journal of Sport and Exercise Psychology 17: $35-53$.

Pelletier LG, Vallerand RJ. 1996. Supervisors' beliefs and subordinates' intrinsic motivation. Journal of Personality and Social Psychology 71: 331-340.

Pelletier LG, Vallerand RJ. 1993. Une perspective humaniste de la motivation: les théories de la compétence et de l'autodétermination. In Introduction à la psychologie de la motivation, Vallerand RJ, Thill E. (eds); Montréal: Etudes vivantes; 233-280.

Perugini M, Conner M. 2000. Predicting and understanding behavioral volitions: the interplay between goals and behaviours. European Journal of Social Psychology 30: 705-731. 
Randall DM, Wolff JA. 1994. The time interval in the intention-behaviour relationship: Meta-analysis. British Journal of Social Psychology 33: 405-418.

Rawsthorne LJ, Elliot AJ. 1999. Achievement goals and intrinsic motivation: A metaanalytic review. Personality and Social Psychology Review 3: 326-344.

Reeve J, Deci E. 1996. Elements of the competitive situation that affect intrinsic motivation. Personality and Social Psychology Bulletin 22: 24-33.

Richer SF, Vallerand RJ. 1998. Construction et validation de l'Echelle du Sentiment d'Appartenance Sociale (ESAS). Revue Européenne de Psychologie Appliquée European Review of applied psychology, 48: 129-137.

Roberts GC. 2001. Understanding the dynamics of motivation in physical activity: The influence of achievement goals on motivational process. In Advances in motivation in sport and exercise, Roberts GC (ed); Champaign, Il.: Human Kinetics Publishers; 1-50. Roberts GC, Treasure DC, Kavussanu M. 1997. Motivation in physical activity contexts: An achievement goal perspective. In Advances in motivation and achievement, Maehr M, Pintrich P (eds); Greenwich, CT: JAI Press; 413-447.

Rupp MT, Segal R. 1989. Confirmatory factor analysis of a professionalism scale in pharmacy. Journal of Social and Administrative Pharmacy 6: 31-38.

Russell DG, Allen JB, Wilson NC. 1996. Youth sport in New Zealand. In Worldwide trends in child and youth sport, DeKnop P, Engstrom LM, Skirstad B, Weiss M (eds); Champaign, IL : Human Kinetics.

Ryan RM. 1982. Control and information in the intrapersonal sphere: An extension of cognitive evaluation theory. Journal of Personality and Social Psychology 43: 450-461. Ryan RM. 1995. Psychological needs and the facilitation of integrative processes. Journal of personality 63 : 397-428. 
Ryan RM, Connell JP. 1989. Perceived locus of causality and internalization:

Examining reasons for acting in two domains. Journal of personality and Social Psychology 57: 749-761.

Ryan RM, Connell JP, Deci EL. 1985. A motivational analysis of self-determination and self-regulation in education. In Research on motivation in education : The classroom milieu, Ames C, Ames RE (eds); New York : Academic Press; $13-51$. Ryan RM, Deci EL. 2000. Self-Determination Theory and the Facilitation of Intrinsic Motivation, Social Development, and Well-Being. American Psychologist 55: 68-78 Ryan RM, Frederick CM, Lepes D, Rubio N, Sheldon K. 1997. Intrinsic Motivation and exercise adherence. International Journal of Sport Psychology 28: 335-354. Ryan RM, Koestner R, Deci EL. 1991. Ego-involved persistence: When free-choice behaviour is not intrinsically motivated. Motivation and Emotion 15: 185-205.

Sallis JF, Patrick K. 1996. Physical activity guidelines for adolescents : A consensus statement. Pediatric Exercise Science 6: 302-314.

Sarrazin P, Guillet E. 2001. "Mais pourquoi ne se réinscrivent-ils plus !" Variables et processus de 1'abandon sportif. In Théories de la motivation et pratiques sportives: état des recherches, Cury F, Sarrazin P (eds); Paris: Presses Universitaires de France; 223254.

Seifriz JJ, Duda J, Chi L. 1992. The relationship of perceived motivational climate to intrinsic motivation and beliefs about success in basket-ball. Journal of Sport and Exercise Psychology 14: 375-391.

Sheeran P, Norman P, Orbell S. 1999. Evidence that intentions based on attitudes better predict behaviour than intentions based on subjective norms. European Journal of Social Psychology 29: 403-406. 
Sheppard BH, Hartwick J, Warshaw PR. 1988. The theory of reasoned action: A metanalysis of past research with recommendations for modifications and future research. Journal of Consumer Research 15: 325-343.

Smith RE, Smoll FL, Curtis B. 1979. Coach effectiveness training: A cognitivebehavioral approach to enhancing relationship skills in youth sport coaches. Journal of Sport Psychology 1: 59-75.

Vallerand RJ. 1997. Toward a hierarchical model of intrinsic and extrinsic motivation. In Advances in Experimental Social Pychology, Zanna MP (ed); New York : Academic Press; $271-360$.

Vallerand RJ, Bissonnette R. 1992. On the predictive effect of intrinsic, extrinsic, and amotivation styles on behaviour: A prospective study. Journal of Personality 60: 599620.

Vallerand RJ, Deci EL, Ryan RM. 1987. Intrinsic motivation in sport. In Exercise and sport science review, Pandolf K (ed); New York: MacMillan; 389-425.

Vallerand RJ. Fortier MS. 1998. Measures of intrinsic and extrinsic motivation in sport an physical activity : A review and critique. In Advances in Sport and Exercise Psychology Measurement, Duda J (ed); Morgantown, WV: FIT; 81-101.

Vallerand RJ, Fortier MS, Guay F. 1997. Self-determination and persistence in a RealLife Setting : Toward a motivational model of high school dropout. Journal of Personality and Social Psychology 72: 1161-1176.

Vallerand RJ, Gauvin LL, Halliwell WR. 1986. Effects of zero-sum competition on children's intrinsic motivation and perceived competence. Journal of Social Psychology 126: $465-472$. 
Vallerand RJ, Grouzet F. 2001. Pour un modèle hiérarchique de la motivation intrinsèque et extrinsèque dans les pratiques sportives et l'activité physique. In Théories de la motivation et pratiques sportives: état des recherches, Cury F, Sarrazin P (eds); Paris: Presses Universitaires de France; 57-95.

Vallerand RJ, Losier GF. 1999. An integrative analysis of intrinsic and extrinsic motivation in sport. Journal of applied sport psychology 11: 142-169.

Vallerand RJ, Pelletier LG, Blais MR, Brière NM, Senécal C, Vallières EF. 1992. The academic Motivation Scale: A measure of intrinsic, extrinsic, and amotivation in education. Educational and Psychological Measurement 52: 1003-1019. Vallerand RJ, Pelletier LG, Blais MR, Brière NM, Senécal C, Vallières EF. 1993. On the assessment of intrinsic, extrinsic, and amotivation in education : evidence on the concurrent and construct validity of the Academic Motivation Scale. Educational and Psychological Measurement 53: 159-172.

Vallerand RJ, Perreault S. in press. Intrinsic and extrinsic motivation in sport : Toward a hierarchical model. In Sport psychology: Linking theory and practice, Lidor R, Bar-Eli M (eds); Morgantown, WV : Fitness Information Technology Inc.

Vallerand RJ, Ratelle C. in press. Intrinsic and extrinsic motivation: A Hierarchical model. In The motivation and self-determination of behavior: Theoretical and applied issues; Deci EL, Ryan RM (eds); Rochester, NY: University of Rochester Press. Vallerand RJ, Rousseau F. 2001. Intrinsic and Extrinsic Motivation in Sport and Exercise: A Review Using the Hierarchical Model of Intrinsic and Extrinsic Motivation. In Handbook of sport psychology (2nd ed.), Singer RN, Hausenblas HA, Janelle CM (eds); New York: John Wiley \& Sons; 389-416. 
Vallerand RJ, Thill EE. 1993. Introduction à la psychologie de la motivation; Montréal: Etudes vivantes.

Walling M, Duda J, Chi L. 1993. The perceived motivational climate in sport questionnaire: construct and predictive validity. Journal of Sport and Exercise Psychology 15: 172-183.

Wankel LM, Mummery WK. 1996. Canada. In Worldwide trends in child and youth sport, DeKnop P, Engstrom LM, Skirstad B, Weiss M (eds); Champaign, IL : Human Kinetics.

Weiss MR, Chaumeton N. 1992. Motivational orientations in sport. In Advances in sport psychology, Horn TS (ed); Champaign, IL.: Human Kinetics; 61-99. 


\section{Footnote}

1- One might suggest that it would have been preferable to assess coaches' behaviour instead of players' perceptions. However, self-determination theory (Deci \& Ryan, 1985, 1991) and the HMIEM (Vallerand, 1997) insist on the fact that it is not the behaviour of others per se that influences one's motivation but rather one's perceptions of such behaviour. In addition, some research (e.g., Pelletier \& Vallerand, 1996; Smith, Smoll, \& Curtis, 1979) revealed that children's perceptions of adults in authority positions are highly consistent with adults' reports of their own behaviour, as well as with independent judges' perceptions of adult behaviour. Thus, it can be assumed that children's perceptions of their social context are roughly equivalent to objective contextual variables. Therefore we feel that our strategy was appropriate.

2- The alpha coefficient of this scale may be regarded as problematic by some researchers. However, as noted by Cronbach (1951), given a small number of items, low alphas can underestimate scale item intercorrelations that are the basis for internal consistency. Given the same average item intercorrelations, this scale would produce an alpha of .70 if there were 5 items. With short scales such as the ones used in this study, the adequacy of the underlying measurement model is generally more indicative of the quality of construct measurement than internal consistency (Pedhazur \& Schmelkin, 1991; see also Vallerand, et al., 1997 for a similar argument). As the results of the structural equation models revealed, the measurement model was adequate.

3- We also conducted a regression analysis to predict dropout behavioural intentions from the motivation scales. Results revealed that three predictors were significant ( $p$ 
$<.05)$ : amotivation $(\underline{\beta}=.46)$, intrinsic motivation toward stimulation $(\underline{\beta}=-.10)$, and intrinsic motivation toward knowledge $(\underline{\beta}=-.31)$.

4- WLS does not assume multivariate normality. However, it does require analysis of an asymptotic covariance matrix of the elements in the variance-covariance matrix, and the asymptotic covariance matrix requires a large sample to get stable estimates. Jöreskog and Sörbom (1993) define the minimum sample size required for estimating asymptotic covariance matrix as $\underline{\mathrm{k}}(\underline{\mathrm{k}}-1) / 2$ cases where $\underline{\mathrm{k}}$ is the number of variables. In this study, the Jöreskog and Sörbom's criteria of sample size was met $(\underline{\mathrm{k}}=105)$.

5- An alternative way of testing the discriminant validity of the constructs consists in examining whether each pair of latent factors could be treated as a single construct by setting each correlation to 1.0 and comparing the constrained model to the original model in which the correlation was free to vary (see Anderson \& Gerbing, 1988). These tests were performed separately for each pair of latent constructs. Chisquare difference tests indicated that each correlation was significantly different from 1.0 (all $\mathrm{ps}<.001)$ thereby supporting the discriminant validity of the constructs in the model.

6- Additional analyses were also carried out to test more precisely (1) the mediator role of behavioural intentions and (2) the moderating effect of self-determined motivation on the intention-behaviour relationship. To test the mediational hypothesis with SEM, we compared the model of Figure 2 with an alternative model that included a direct path between self-determined motivation and behaviour (see Perugini \& Conner, 2000). This second model yielded reasonable fit indices $\left[\chi^{2}(78)\right.$ $=202.97, \underline{\mathrm{p}}<.001 \mathrm{GFI}=.99 ; \mathrm{NFI}=.99 ; \mathrm{CFI}=.99 ; \mathrm{RMSR}=.088]$, but the direct 
path from self-determined motivation to behaviour was not significant $(\mathrm{t}=0.87)$. The comparison between the two models suggested that the addition of this path did not improve the fit $\left[\Delta \chi^{2}(1)=0.77, \underline{\mathrm{ns}}\right)$, hence the simplest model (mediated model) should be preferred. Inspection of the relevant parameters showed that the three criteria for mediation listed by Baron and Kenny (1986) were fully achieved: there is (1) a substantial influence of the independent variable on the mediator $(\beta=-0.79)$, (2) a substantial influence of the mediator on the outcome variable $(\beta=0.55)$, and (3) no significant direct paths between the independent variable and the outcome variable whereas this one is significant $(\beta=-0.28)$ when the mediator is deleted. Besides, as suggested by an anonymous referee, behavioural regulations are likely to moderate the intention-behaviour relationship, in that under controlling forms of behavioural regulation, high intention to persist (i.e., low intention to drop out) is less likely to predict adherence than high intention under autonomous forms of regulation. To investigate this possibility, we performed hierarchical multiple regression analyses in which behaviour was predicted from intention and selfdetermined motivation (step 1) and then from the interaction terms between the two (step 2). Following Aiken and West's (1991) guidelines for testing interactions, the independent variables were standardised. The interaction did not reach significance for behaviour $(\underline{\beta}=0.03, \underline{\mathrm{ns}})$. Consequently, there was no evidence for the moderating effect of self-determined motivation.

7- Additional analyses were carried out to determine whether the paths from perceived autonomy, competence, and relatedness to motivation were statistically different one from each other. In each one of these models, two paths were constrained to equality (e.g., the competence-motivation path, $\beta=.23$ was constrained to equality with the 
autonomy-motivation path, $\underline{\beta}=.78$ ). The chi-square from these models was then compared with that from our original model. A significantly higher value for the "equality" model would indicate that the fit of this new model is lower that that of the original model and thus that the two betas are significantly different (see Vallerand et al., 1997). The results from these analyses revealed a significantly higher value for the three equality models (all $\Delta \chi^{2}(1) \geq 8.9, p<.01$ ). Thus, it can safely be concluded that all the three paths were statistically different from each other.

8- To address these concerns, we carried out an analysis in order to took into account the fact that the players were nested in multiple teams. First of all, we only retained teams which had a number of players higher than 9 (i.e., 12 teams for a sample of 135 players). Next, all correlations were rendered independent from teams with the following procedures (see Madon, Jussim, Keiper, Eccles, Smith, Palumbo, 1998): (1) we created a dummy variable for each team, (2) we used these dummy coded team variables to predict all the variables used in this study (i.e., the 8 main variables), and (3) we saved the residuals from these analyses and used them as input data (thereby removing the basic non-independence between teams) to test the proposed model using path analysis models. The results showed adequate fit indices $(\mathrm{GFI}=.96 ; \mathrm{NFI}=.95 ; \mathrm{CFI}=.96 ; \mathrm{RMSR}=.08)$, and a very great homogeneity of the relations between variables with those found in figure 2 . The only noteworthy different relation is the significant path from ego-involving climate to perceived relatedness $(\underline{\beta}=-.25)$, which is in conformity with our hypotheses. Overall, the results from these additional analyses provide additional support for the validity of the model. 
$\underline{\text { Table } 1}$

Means and Standard Deviations of the Motivational Subscale and Behavioral Intentions Scores for Dropout and Persistent Players

\begin{tabular}{|c|c|c|c|c|c|}
\hline \multirow[b]{2}{*}{ Subscale } & \multicolumn{2}{|c|}{$\begin{array}{l}\text { Dropout players } \\
\quad(\mathrm{n}=74)\end{array}$} & \multicolumn{2}{|c|}{$\begin{array}{l}\text { Persistent players } \\
\quad(\mathrm{n}=261)\end{array}$} & \multirow{2}{*}{$\begin{array}{c}\underline{F}(1,333) \\
\underline{p}\end{array}$} \\
\hline & $\underline{\mathrm{M}}$ & $\underline{\mathrm{SD}}$ & $\underline{\mathrm{M}}$ & $\underline{\mathrm{SD}}$ & \\
\hline Intrinsic Motivation - Stimulation & 5.17 & 1.32 & 5.55 & 1.10 & $<.05$ \\
\hline Intrinsic Motivation - Knowledge & 4.79 & 1.40 & 5.26 & 1.14 & $<.01$ \\
\hline Intrinsic Motivation - Accomplishment & 4.85 & 1.32 & 5.52 & 1.11 & $<.0001$ \\
\hline Identified Regulation & 4.22 & 1.38 & 4.47 & 1.27 & $\underline{\mathrm{ns}}$ \\
\hline Introjected Regulation & 4.06 & 1.43 & 4.26 & 1.55 & $\underline{\mathrm{nS}}$ \\
\hline External Regulation & 2.53 & 1.24 & 2.64 & 1.19 & $\underline{\mathrm{nS}}$ \\
\hline Amotivation & 1.65 & 0.95 & 1.40 & 0.73 & $<.05$ \\
\hline Behavioral Intentions & 3.86 & 1.91 & 1.96 & 1.25 & $<.0001$ \\
\hline
\end{tabular}

Note. Scores ranged from 1 to 7 and are based on four items for each of the 8 subscales. Means differ significantly at $p$ value listed. 
$\underline{\text { Table } 2}$

Means and Standard Deviations for the Motivational Antecedent and Mediating Variable Subscales for Dropout and Persistent Players

\begin{tabular}{|c|c|c|c|c|c|}
\hline \multirow[b]{2}{*}{ Subscale } & \multicolumn{2}{|c|}{$\begin{array}{l}\text { Dropout players } \\
\quad(\mathrm{n}=74)\end{array}$} & \multicolumn{2}{|c|}{$\begin{array}{l}\text { Persistent players } \\
(\mathrm{n}=261)\end{array}$} & \multirow{2}{*}{$\begin{array}{c}\underline{F}(1,333) \\
\mathrm{p}\end{array}$} \\
\hline & $\underline{\mathrm{M}}$ & $\underline{\mathrm{SD}}$ & $\underline{\mathrm{M}}$ & $\underline{\mathrm{SD}}$ & \\
\hline \multicolumn{6}{|l|}{ Motivational mediators : } \\
\hline Perceived handball competence & 3.14 & 1.35 & 3.59 & 1.35 & $<.05$ \\
\hline Perceived handball autonomy & 5.70 & 1.54 & 6.31 & 1.10 & $<.001$ \\
\hline Perceived handball relatedness & 4.81 & 1.49 & 5.56 & 1.32 & $<.0001$ \\
\hline \multicolumn{6}{|l|}{ Motivational antecedents (perceived climate) } \\
\hline Ego involving climate & 3.41 & 1.12 & 3.18 & 1.07 & $<.10$ \\
\hline Task involving climate & 5.24 & 1.02 & 5.55 & 0.90 & $<.05$ \\
\hline
\end{tabular}

Note. Scores ranged from 1 to 7 . Means differ significantly at $\mathrm{p}$ value listed. 
Figure caption

Figure 1. Measurement model (CFA) of the hypothesised seven-factor structure. Circles represent latent constructs and squares represent measured variables (composite scores). All parameters are standardised and significant at $\mathrm{p}<.05$. Residual variances are shown in small circles, and standard errors in parentheses.

Figure 2. Structural equations analysis of the 4-stage causal sequence of the Hierarchical Model (Vallerand, 1997). All parameters are standardized and significant at $p<.05$. Residual variances are shown in small circles. 


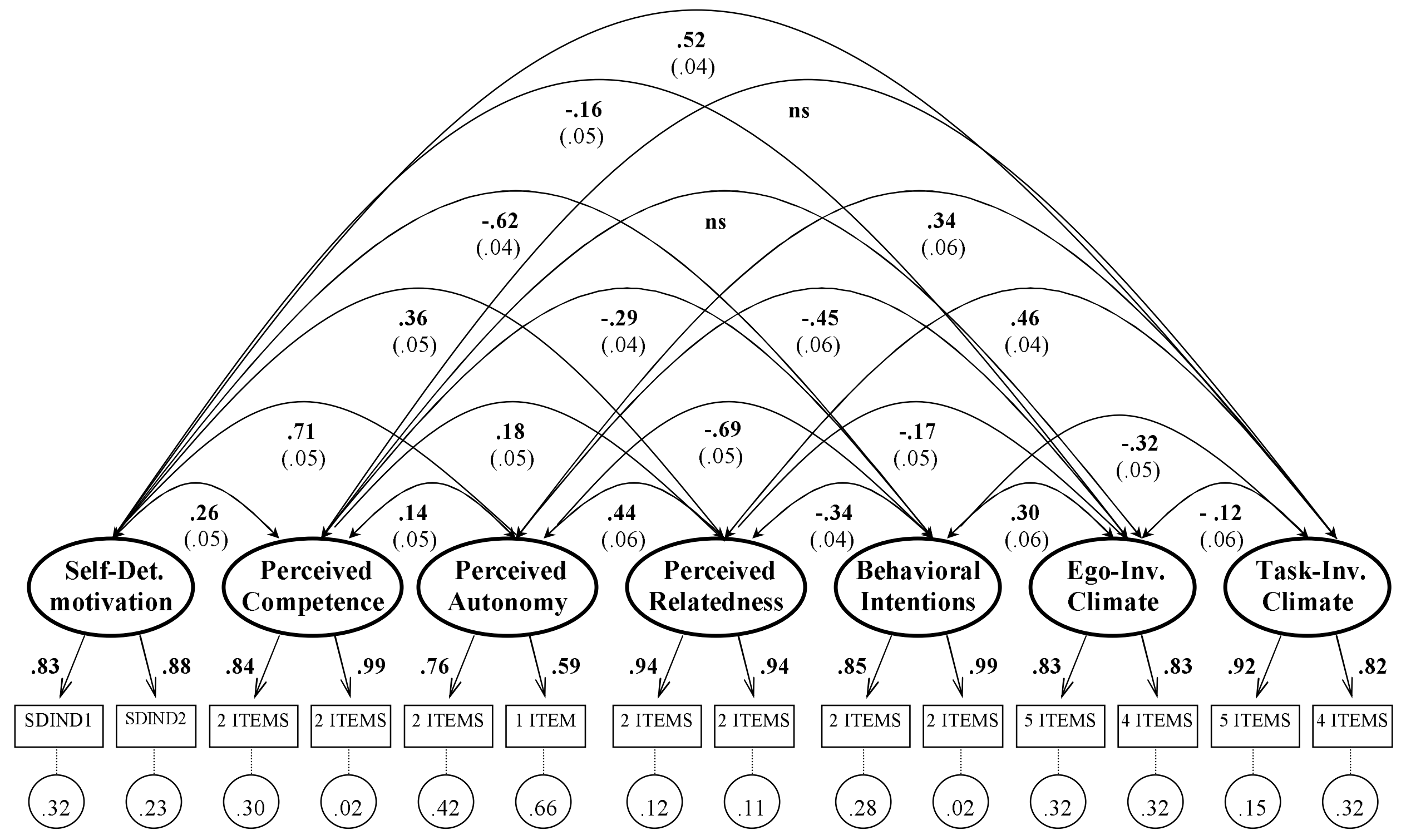




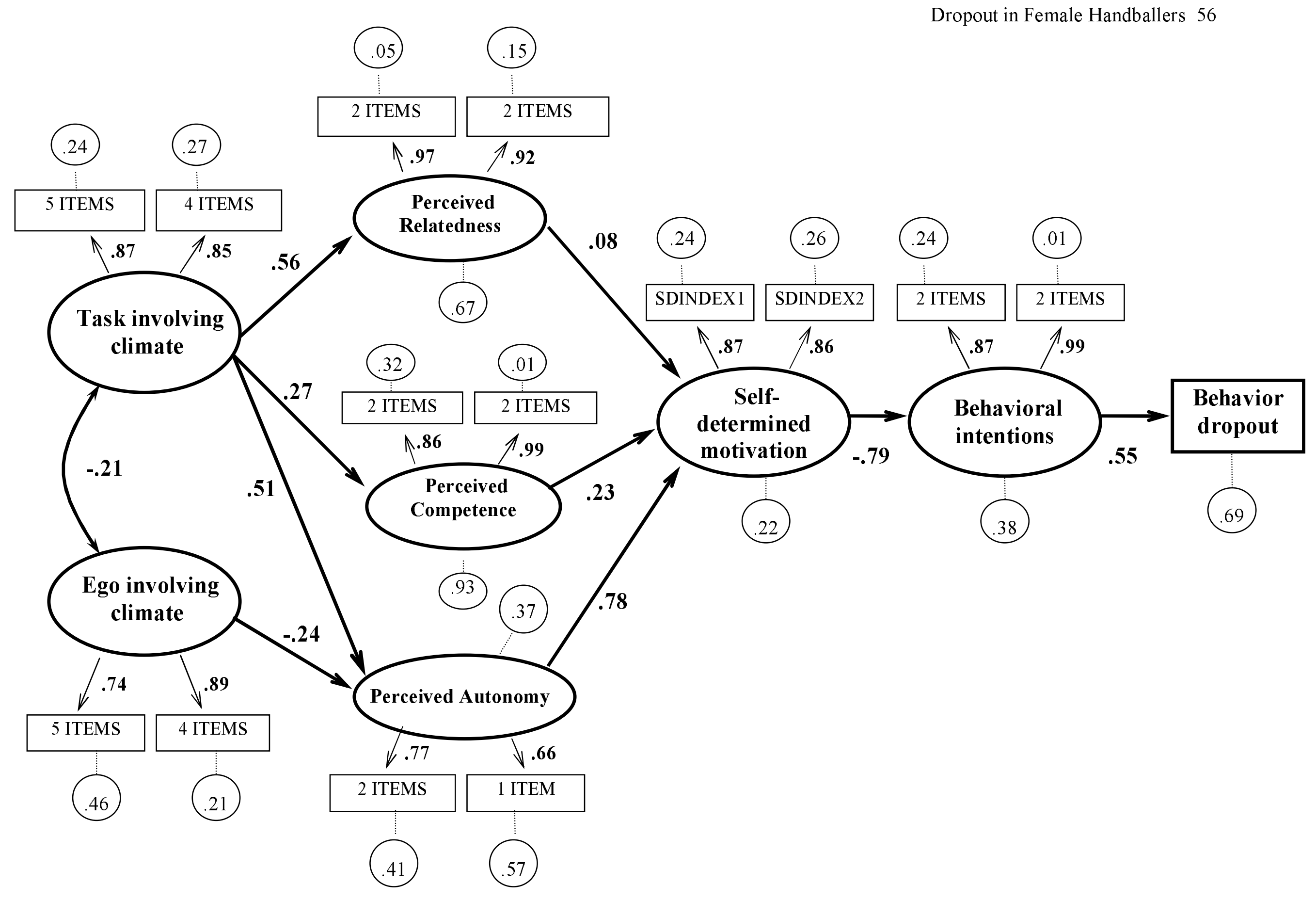

